\title{
Gender Differentials in the Adoption of Drought-Tolerant Maize Varieties among Farmers in the Northern Region of Ghana
}

\author{
Gaya, H. I.M. ${ }^{1}$, Kehinde A. D. ${ }^{2}$, Tahir, A.D. ${ }^{1 *}$, Bamire, A. S. ${ }^{2}$ and Ibrahim, F.J ${ }^{3}$ \\ 1.Department of Agricultural Economics, University of Maiduguri, Maiduguri, Borno State, Nigeria \\ 2.Obafemi Awolowo University, Ile-Ife, Nigeria \\ 3.School of Vocational Education, Department of Agriculture, Federal College of Education Technical, Gombe
}

\begin{abstract}
This study examined gender differences in farmers' adoption of drought-tolerant maize (DTM) varieties in northern region of Ghana. Specifically, it described the socio-economic characteristics of the farmers by gender; determined their rate of adoption of the DTM varieties; and analyzed the factors affecting the rate of adoption of the varieties. The study was conducted in the Northern region of Ghana. Simple random sampling technique was used to obtain data from 600 respondents, comprising 551 males and 49 females. Data were collected with the use of a survey questionnaire that contained questions on respondents' socio-economic characteristics such as age, years of schooling, household size, farm size, access to credit, level of awareness and adoption of DTM varieties and extension contact, among others. Data were analyzed using descriptive statistics and probit regression model. The results for the entire respondents showed average values of 49.75 years for age, 10.8 for household size, with a significant difference $(\mathrm{p}<0.05)$ between male and female farmers for each of the variables. Average farm size of 3.38 ha, with a significant difference $(p<0.01)$ between male and female farmers for the variables. The adoption rate of DTM was $13.3 \%$ in the entire sample with a significant difference $(p<0.05)$ between male $(13.4 \%)$ and female farmers (12.2\%). The determinants of adoption of DTM varieties for both male and female farmers were age of the household head, education, source of seed, and level of awareness, specific to male farmers was educational status of the respondents while farm size was specific to female famers. It was concluded that policy strategies aimed at improving the uptake of DTM varieties must consider equality in male and female farmers' access to resources such as credit, labour and land.
\end{abstract}

Keywords: Gender, Drought-tolerant, Maize varieties, Adoption, Ghana.

DOI: $10.7176 / \mathrm{JBAH} / 11-20-04$

Publication date:October $31^{\text {st }} 2021$

\subsection{INTRODUCTION}

Maize is an important cereal crop in Ghana accounting for $50 \%$ to $60 \%$ of its current cereal production (Morris et al., 2001; Akramov and Malek, 2012). Due to the eroding profitability of many cash crops such as oil palm and cocoa, maize attracted the attention of commercial farmers. Though it has not achieved the economic importance of these cash crops, it is major source of food and income to the teeming populace. Thus, accounts for $45 \%$ of the income among smallholder farmers. Though, maize farms are cultivated by both men and women, but interestingly, women manage the maize farms and exercise complete discretion over the sale of output (Morris et al., 1999).

Despite Ghana's self-sufficient potential in maize production, its supply has not met the demand of the people. Currently, land area allocated to maize production in the country is approximately 1 million ha, with average production and yield about 1.65 million MT and 1.74 metric tons (MT) per ha against the potential yield of 6 metric tons per ha (MoFA, 2013). In recent years, maize consumption has out grown the production. The per capita consumption of maize was estimated to be $44 \mathrm{~kg} / \mathrm{person} / \mathrm{year}$. This led to $1.83 \%$ increase in the aggregate demand per annum with $5.4 \mathrm{~kg}$ per person increase per year. A climate change in the manifestation of drought was observed to be a major cause of low maize yield (Slingo et al., 2005). Others are infestation by the parasitic weed (Striga hermonthica) and foliar diseases of maize (Sserunkuuma et al., 2001).

The recurrent droughts have affected the livelihoods of many resource-poor rural farming households (Hodson et al., 2002). To contribute to the continental efforts to improve livelihoods in the face of climate change, the Drought Tolerant Maize for Africa (DTMA) initiative was established which aimed at developing and disseminating DT maize varieties to farming households in the country (Alexander et al., 2010). This effort has met with success, as DT maize varieties are now grown in reasonable quantities in some regions of the country (Olaniyi and Manyong, 2007). Inspite of this, there is still a huge gap between demand and supply (Babatunde, 2008). This could be traced to gender stratification in the distribution of productive resources, and access to information and technology ((Langyintuo, 2005; Simonyan et al., 2012).

Despite the important role played by women in agriculture, very few own or control productive resources such as land, credit, technical services, market outlets, information etc (Opio, 2003 Commonwealth secretariat 2001). This could be linked to their low socioeconomic status, therefore rendering them unable to make important decisions over use of productive resources leading to little or no benefits accruing from farm production. Gender inequality is a problem which has characterized the agricultural sector (Olagunju et al., 2012). Men and Women 
are affected differently in their operation by varying factors such as markets and socio- economic status. However, women are more constrained than their men counterparts in terms of access to credits, agricultural inputs, and information technology (Ndukwu et al., 2010). In view of this, understanding the gender variations in the adoption of DTM varieties becomes imperative.

This paper aimed to study the gender differentials in the adoption of DTM varieties in the Northern part of Ghana. Specifically, it describes the socio-economic characteristics of maize farmers in the area by gender; estimates their adoption rate of DTM varieties; and determines the factors that influence the rate of adoption of the varieties.

\section{Methodology}

This section describes the survey locations, the sampling procedure and sample size, data collection methods as well as the techniques of data analysis.

\subsection{Study area, sampling procedure and sample size}

The survey was conducted in Northern region of Ghana with high levels of maize production in each country, and in zones where Bamire et al, 2010 stated to be drought probability risk of between 40 and $60 \%$. Simple random sampling was used to select respondents from the northern region of Ghana. 3 regions were selected, and in each region 200 respondents were chosen to make 600 in total, comprising 551 males and 49 females. Data were collected with the use of a survey questionnaire that contained questions on respondents' socio-economic characteristics such as age, years of schooling, household size, farm size, access to credit, level of awareness and adoption of DTM varieties and extension contact, among others.

\section{Table 1: Respondents distribution}

\begin{tabular}{|l|l|l|l|}
\hline COUNTRY & REGION/STATE & VILLAGES & RESPONDENTS \\
\hline GHANA & Brong-ahafo region & 20 & 200 \\
\hline GHANA & Upper east region & 20 & 200 \\
\hline GHANA & Upper west region & 20 & 200 \\
\hline TOTAL & & 60 & 600 \\
\hline
\end{tabular}

\subsection{Analytical techniques}

Data were analysed with the use of descriptive statistics and Probit regression technique.

\subsubsection{Descriptive statistics}

Descriptive statistics was used to describe gender differences among study variables. It involved the computation of means, standard deviation, frequency counts and percentages.

\subsubsection{Probit regression model}

\subsubsection{Theoretical Probit regression model}

Probit regression was used to determine the factors influencing the adoption of DTM varieties for the entire sample and by gender. Probit is a binary choice model that can only assume two values of 1 or zero and tries to explain the probability that a farmer will choose an improved variety over a traditional variety based on some set of complex factors (Akudugu et al., 2012).

The marginal effect of the variables is calculated using the formula:

$$
\text { Marginal effects }=\mathrm{B}_{\mathrm{i}} \varnothing(\mathrm{Z})
$$

Where $\mathrm{B} i$ are the coefficients of the variables and $\varnothing(Z)$ are the cumulative normal distribution value associated with the mean dependent variable from the probit estimation.

\subsubsection{Empirical Probit regression model}

In this study, the dependent variable is the probability of adoption of DTM varieties by the farmers.

The estimated Probit model is specified as follows:

$\mathrm{Y}_{\mathrm{i}}=\beta_{0}+\beta_{1}$ AGEHHED $+\beta_{2}$ FFEDU $+\beta_{3}$ HHSIZE $+\beta_{4}$ FAMSIZE $+\beta_{5}$ MAZAREA $+\beta_{6}$ ACECRED $+\beta_{7}$ EXTEN + $\beta_{8}$ DROUGAFFEC $+\beta_{9}$ FEILDDAY $+\beta_{10}$ LIVESTCK $+\beta_{11}$ FERTILIZ $+\beta_{12}$ IRRIGATION $+\beta_{13}$ SELFSUFFICIEN

$+\beta_{14}$ SOURCSEED $+\beta_{15}$ AWAR $+e_{i}$

Where,

$\mathrm{Y}_{\mathrm{i}}$ is the dependent variable, the probability of adoption of DTM varieties (Dummy: Adopt, 1; Non-adoption, 0)

The independent variables are:

AGEHHED is age of the farmers (years)

FFEDU is years of schooling (years)

HHSIZE is farm household size (\#)

FAMSIZE is farm size (ha)

MAZAREA is the land area allocated to maize production (ha)

ACECRED is access to credit ( $1=$ Access, $0=$ Non access $)$

EXTEN is access to extension services $(1=$ Yes $0=$ No) 
DROGAFFECT is affected by drought $(1=$ Yes, $0=$ No)

FEIDDAY is participation in field days $(1=$ Yes, $0=$ No)

LIVESTCK is number of livestock (\#)

FERTILIZ is fertilizer application $(1=$ Yes, $0=$ No)

IRRIGATION is irrigation application $(1=$ Yes, $0=\mathrm{No})$

SELF SUFFICIEN is self-sufficiency in maize production $(1=\mathrm{Yes}, 0=$ No)

SOUCESED is source of seeds (dummy variable $0=$ Informal source, $1=$ Formal source)

AWAR is awareness of DTM varieties $(1=$ Yes, $0=$ No)

$\mathrm{e}_{\mathrm{i}}$ is random error term.

\section{Result and Discussion}

\subsection{Gender of the respondents}

Figure 1 reveals the gender analysis of the respondent in Ghana. About $92 \%$ of the respondent was male while only $8 \%$ was female. This shows that men dominate agricultural activities in the study area. Due to some cultural values and norms, males have freedom of mobility and participation in meetings and consequently have greater access to information (Bamire et al., 2012; Etwire et al., 2013).

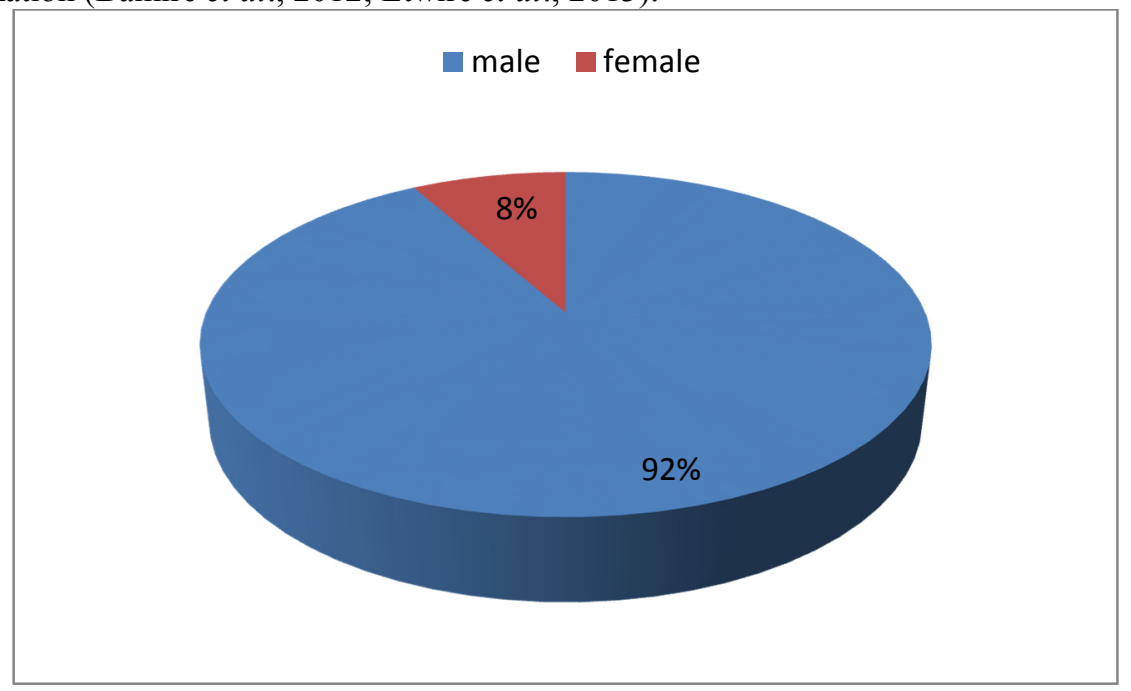

Figure1: gender analysis of respondents

\subsection{Socio-economic characteristics of maize farmers}

Table 1 shows the socio-economic characteristics of farming households by gender. The average age of respondents in the entire sample was $49.8 \pm 12.21$ years with a significant difference $(\mathrm{p}<0.05)$ between the mean age of male $(50 \pm 12$ years) and female $(45 \pm 11$ years) farmers. This suggests that male maize farmers were relatively older than their female counterparts in the study area. Education gives farmers the opportunity to obtain and process information relating to improved technologies. The average number of years of schooling was 3.6 \pm 1.1 years for the entire sample, with no significant difference between that of male farmers $(3.6 \pm 2.1)$ years and female farmers (4.2 \pm 3.4$)$. The mean farm size was $3.4 \pm 2.2$ ha for the entire sample of farmers. There was a significant difference $(\mathrm{p}<0.01)$ between the male $(3.5 \pm 2.2)$ ha and the female $(1.8 \pm 1.2)$ ha farmers. This suggests that male farmers have relatively larger farms than the female and this might be attributed to the socio-cultural norms that restrict access to land for women in the study area (Bamire et al., 2012; Etwire et al., 2013; Doss, 2015 ). The average land area allocated to DTM varieties was $2.3 \pm 1.7$ ha for the entire sample, with no significant difference between male farmers $(2.3 \pm 1.7)$ ha and female farmers $(2.0 \pm 1.3)$ ha. This may further suggest that males have better access over land resources, therefore likely to try new planting of DTM varieties. Only $6.8 \%$ of the entire sample had access to credit, with variations between male farmers $(7.4 \%)$ and the females $(0 \%)$. This indicates that female farmers have no access to credit. About $50 \%$ of the entire sample received information about DTM from agricultural extension services, $49 \%$ of whom were male farmers and $59 \%$ female farmers. This suggests that both male and female farmers receive information about DTM varieties from the same source, though women have better access to information than men. About $55 \%$ of the entire sample farms were affected by drought, $43 \%$ were male farmers and $53 \%$ female farmers. This suggests female headed households are vulnerable to food insecurity and poverty in face of climate changes (drought manifestation). Also, about 91 percent of the entire sample of farmers participated in field days, majority $(92 \%)$ of who were male though $87 \%$ were female.

The average household size for the entire sample was about $10 \pm 6.4$ persons per household, with a significant difference $(p<0.05)$ between male headed households $(11 \pm 6)$ and female headed households $(9 \pm 6.4)$. This could 
indicate that male-headed households have more access to family labour than female-headed households for maize production operations. The source of seed influences the type of varieties that would be used in a particular planting season. About $67 \%$ of the entire sample had access to formal sources of seed, with a little variation between male $(67 \%)$ and the female farmers $(65 \%)$. The possession of livestock is an indicator of a availability of wealth for the farmers. About $62 \%$ of the entire sample own livestock, $63 \%$ of which are owned by male farmers and $53 \%$ by female farmers. Only $1.2 \%$ of the farmers irrigated their maize farms, comprising 1.1 male and $2 \%$ female farmers while about $60 \%$ of the entire respondents were self-sufficient in maize production, comprising $61 \%$ of the male and $49 \%$ of females.

Table 1: Socio economic characteristics of the respondents

\begin{tabular}{lllll}
\hline Variable & All respondents & Male & Female & t-test \\
\hline Age(years) & $49.75(12.21)$ & $50.12(12.27)$ & $45.55(11.57)$ & $2.51^{* *}$ \\
Years of schooling & $3.6(1.12)$ & $3.56(2.10)$ & $4.2(3.36)$ & 0.913 \\
Household size (\#) & $10.8(6.45)$ & $11.01(6.43)$ & $8.93(6.48)$ & $2.16^{* *}$ \\
Farm size (ha) & $3.38(2.20)$ & $3.52(2.22)$ & $1.81(1.21)$ & $5.33^{* * *}$ \\
Land allocated to maize production (ha) & $2.28(1.72)$ & $2.31(1.75)$ & $2.00(1.34)$ & 1.20 \\
Access to credit (\%) & 6.8 & 7.4 & 0 & 5.2 \\
Access to extension services (\%) & 50.2 & 49.4 & 53.1 & \\
Affected by drought (\%) & 55.3 & 43.9 & 87.8 \\
Field days (\%) & 91.8 & 92.2 & 53.1 \\
Own livestock (\%) & 62.5 & 63.3 & 91.8 \\
Applied fertilizer (\%) & 95.7 & 96.0 & 2.0 \\
Applied irrigation (\%) & 1.2 & 1.1 & 46.9 \\
Self-sufficiency (\%) & 60.5 & 61.7 & 65.3 \\
Formal source of seed (\%) & 67.2 & 67.3 &
\end{tabular}

Note: () figures in parentheses are standard deviations, $* * *$ indicates significant at $1 \%, * *$ indicates significant at $5 \%$.

\subsection{Awareness and Adoption of DTM varieties}

The rate of adoption of DTM varieties for the entire sample of farmers and by gender is shown in Figure 2. The level of awareness of any technology stimulates its adoption. On the average, about $29 \%$ of the entire sample was aware of the DTM varieties, with relatively larger proportion of male farmers $(29.9 \%)$ than female farmers $(24.5 \%)$. This may suggest that male farmers will likely adopt DTM varieties. The adoption rate by the entire sample was $13.3 \%$, with males having a relatively larger proportion $(13.4 \%)$ and females $(12.2 \%)$. This could be ascribed to freedom of male to own and exercise control over resources such as land, labour, and credit as compared to the females, which invariably give them more access to information on new technologies for their adoption (Bamire et al., 2012; Etwire et al., 2013).

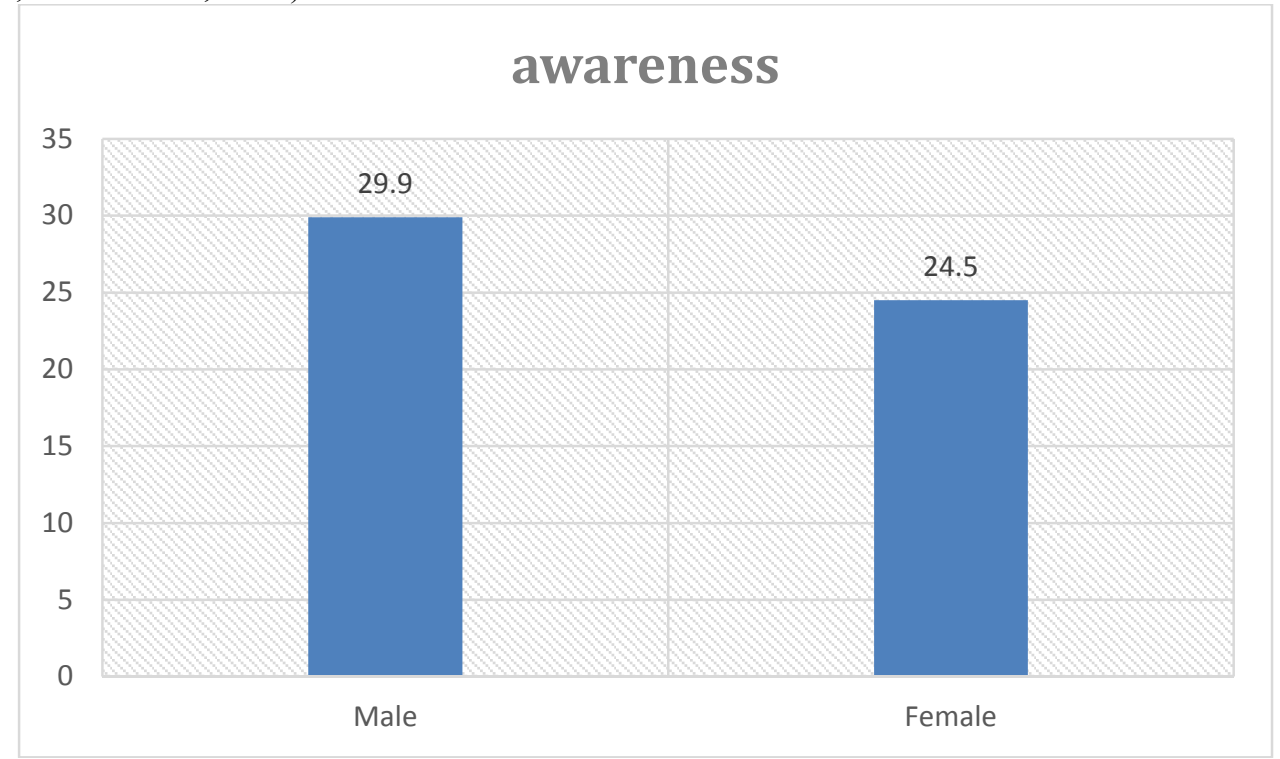

Figure 1: Awareness of Drought tolerant maize varieties 


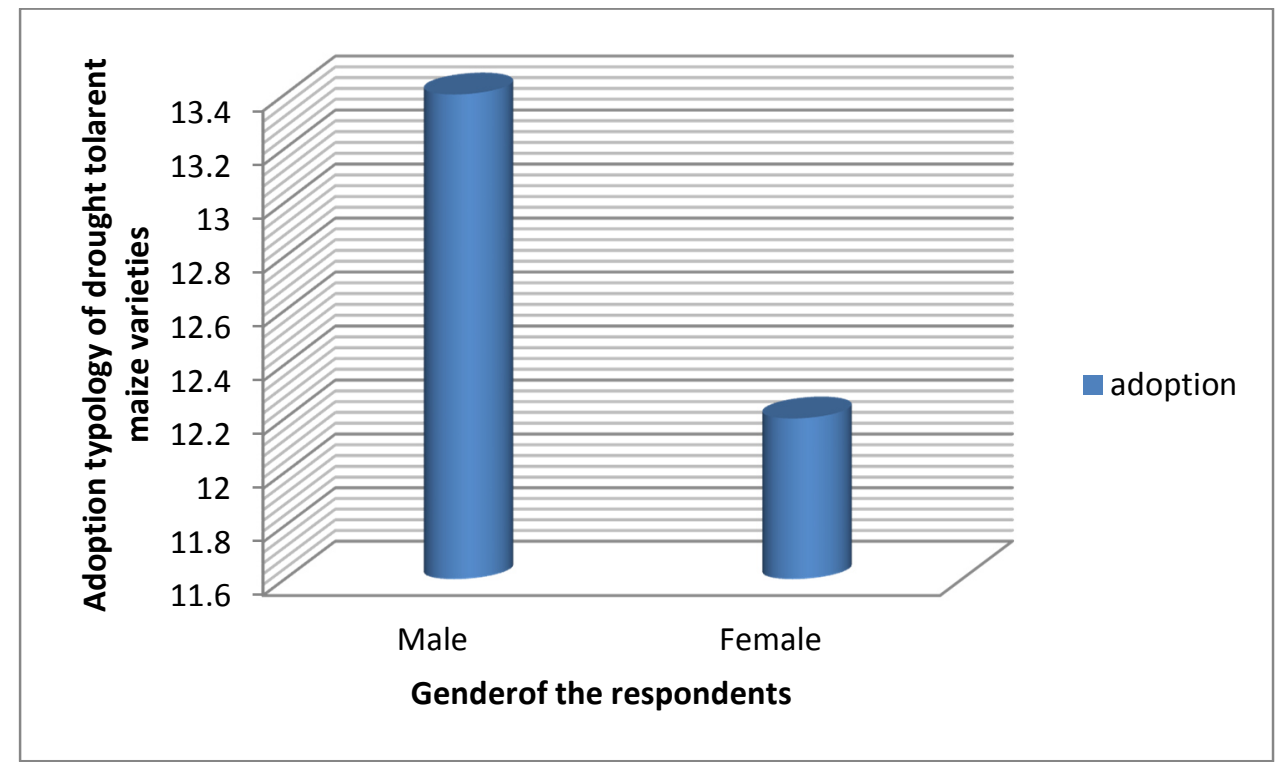

Figure 2: Adoption of Drought tolerant maize varieties

Table 2: Factor influencing the adoption of DTM varieties

Table presents the factors influencing farmers' adoption of DTM varieties among the respondents by gender.

\begin{tabular}{|c|c|c|c|}
\hline Variables & $\begin{array}{l}\text { All } \\
\text { Respondents } \\
(\mathrm{n}=600)\end{array}$ & $\begin{array}{l}\text { Male } \\
(\mathrm{n}=551)\end{array}$ & $\begin{array}{c}\text { Female } \\
(n=49)\end{array}$ \\
\hline Age & $0.016(2.02)^{* *}$ & $0.107(1.25)$ & $-0.328(-1.04)$ \\
\hline Education & $0.045(2.46)^{* *}$ & $0.048(2.55)^{* *}$ & $0.025(0.18)$ \\
\hline Household size & $0.161(1.02)$ & $0.030(1.78)^{*}$ & $0.118(1.53)$ \\
\hline Farm size & $0.066(1.61)$ & $0.062(1.49)$ & $1.572(2.19)^{* *}$ \\
\hline Land allocated to maize production & $-0.023(-0.42)$ & $-0.023(-0.42)$ & $1.094(1.45)$ \\
\hline Access to credit & $-0.320(-0.97)$ & $-0.333(-1.01)$ & $-0.581(-1.15)$ \\
\hline Extension service & $0.111(0.59)$ & $0.152(0.79)$ & $2.056(1.09)$ \\
\hline Drought severity & $0.083(0.05)$ & $0.001(0.01)$ & $1.625(1.34)$ \\
\hline Field days & $0.444(0.72)$ & $0.359(0.56)$ & \\
\hline Livestock & $-0.467(2.10)^{* *}$ & $-0.494(-2.15)^{* *}$ & $-0.187(-0.22)$ \\
\hline Fertilizer & $0.270(0.57)$ & $0.010)(0.02)$ & \\
\hline Self sufficiency & $0.206(1.07)$ & $0.243(1.21)$ & $-1.925(-3.15) * * *$ \\
\hline Source of seed & $0.454(2.24)^{* *}$ & $0.529(2.49)^{* *}$ & $0.198(1.75 *$ \\
\hline Awareness & $1.933(9.16)^{* *}$ & $1.932(9.12) * * *$ & $1.613(2.52)^{* *}$ \\
\hline Constant & $4.533(4.94)^{* *}$ & $4.131(4.11)^{* * *}$ & $4.781(4.72)^{* * *}$ \\
\hline Pseudo $\mathrm{R}^{2}$ & 0.424 & 0.417 & 0.459 \\
\hline Log likelihood & -135.131 & -126.148 & -103.810 \\
\hline Prob $>$ chi $^{2}$ & 0.0000 & 0.0000 & 0.0000 \\
\hline
\end{tabular}

*** Significant at $1 \%, * *$ Significant at $5 \%, *$ Significant at $10 \%$. Figures in parentheses ( ) are t-values.

From Table 2, Age, education, livestock, source of seed, and awareness influenced the adoption of DTM varieties in the entire sample. However, the coefficients of age, education, source of seed and level of awareness of DTM had positive signs. This implies that a unit increase in any of these variables, the rate of adoption increases by; 0.016 units for age, education (0.045), source of seed (0.454) and level of awareness of DTM (1.993) units (Ayinde et al., 2013). Similarly, the coefficients of livestock owned had negative signs. This implies that a unit increase in this variable, rate of adoption of DTM varieties decreases by 0.494 units.

A gender analysis of the factors influencing the adoption of DTM varieties showed some variations. The coefficients of education, household size, source of seed and level of awareness significantly influenced the adoption of DTM varieties among male farmers at different levels of probability. The coefficients of education, household size, source of seed and level of awareness had positive signs, implying that a unit increase in any of these variables, the rate of adoption of DTM varieties increased by; $0.048,0.030,0.529$ and 1.933 units, respectively. Also, the negative coefficient of number of livestock owned implies that these variables reduce the rate of adoption by 0.494 units.

Meanwhile, farm size, self-sufficiency, source of seeds, and level of awareness significantly influenced the 
adoption of DTM varieties among female farmers. The coefficients of three of the variables; farm size, source of seed, and level of awareness had positive signs while the coefficient of self-sufficiency had negative sign. The positive signs suggest a positive influence on adoption of DTM varieties. A unit increase in farm size, awareness and source of seeds increased the rate of adoption of DTM varieties by $1.572,1.613$ and 0.198 units, respectively. Similarly, the negative signs of coefficients show a negative influence on adoption of DTM varieties, such that for every unit increase in self-sufficiency, there is a reduction in the rate of adoption of DTM varieties by 1.925 units. This suggests that while strategies targeted at promoting male farmers adoption of DTM varieties should consider education, increasing female uptake of DTM varieties should focus on farm size.

\section{Conclusion}

Maize is grown by vast majority of farming households in Northern Ghana. There are gender variations in the socio-economic characteristics of both male and female farmers and their level of awareness and adoption of DTM varieties. Male farmers were relatively older than their female counterparts, with significant differences between their years of schooling and farm sizes. Male farmers have larger farms than the female as a result of socio-cultural norms that attribute the control and access to land to men. The significant difference between male and female farmers' farm size gives male farmers opportunity to better try new innovations such as planting DTM varieties (Abdoulaye et al., 2012). Though both male and female farmers receive information about DTM varieties from the same source - government extension services, though more females than males sourced for the information. The level of adoption of DTM varieties by maize farmers in Northern Ghana is relatively very low, with males having a relatively larger proportion than the females. Consequently, more males (13.4\%) adopted the variety than females $(12.2 \%)$. This implies that DTM varieties should further be promoted in the study area, particularly among female farmers to enhance their adoption. The factors that significantly influenced the adoption of DTM varieties in the study area are age, education, livestock owned, source of seed and level of awareness. However, education was specific to male farmers, while farm size and self-sufficiency were specific to females (Bamire et al., 2012; Abdoulaye and Anyebe, 2013). This suggests that while strategies targeted at promoting the adoption of DTM varieties among male farmers should consider educational status of the farmers, increasing female uptake of DTM varieties should focus on increasing the hectares of farm available to female farmers. This could be made possible through intensive education programmes by effective and efficient extension services during field demonstrations and farmer field days. Government should also ensure gender equality in the access to resources such as land, labour and credit among farmers in Northern Ghana.

\section{REFERENCES}

Abdoulaye, T. and O. Anyebe (2013). Promoting the use of drought tolerant maize in Nigeria. $R \& D$ Review 10 : 22-3, ISSN 2071-3681.

Akudugu, M., Guo, E., Dadzie, S. (2012) Adoption of Modern Agricultural Production Technologies by Farm Households in Ghana: What Factors Influence their Decisions? Journal of Biology, Agriculture and Healthcare 2(3)

Akramov K, Malek M (2012). Analyzing Profitability of Maize, Rice, and Soybean Production in Ghana: Results of PAM and DEA Analysis. Ghana Strategy Support Program (GSSP) Working P. 0028.

Alexander, C., \& Van Mellor, T. (2005). Determinants of corn rootworm resistant corn adoption in Indiana. AgBioForum, 8(4), 197-204

Ayinde, O.E, Abduolaye T., Olaoye, G., J.A. Akangbe (2013). Gender and Innovation in Agriculture: A Case Study of Farmers' Varietal Preference of Drought Tolerant Maize in Southern Guinea Savannah Region of Nigeria. Albanian J. Agric. Sci. 12(4): 617-625.

Bamire, A. S., T. Abdoulaye, D. Sanogo and A. Langyintuo (2010). Characterization of maize producing households in the dry savanna of Nigeria. Country Report - Nigeria, IITA, Ibadan, Nigeria, 46pp.

Babatunde, R.O., S.B. Fakayode and A.A. Obafemi (2008). Fadama maize production in Nigeria: Casa study from Kwara State. Res. J. Agric. Biol. Sci., 4: 340-345.

Commonwealth secretariat, (2001). Gender Mainstreaming in Agriculture and Rural Development. A Reference Manual for Governments and Other Stakeholders. pp 1 -

24. ISBN: 0-85092-606-8.

Doss, C. R. (2015) Women and agricultural productivity: what does the evidence tell us? Yale University Economic growth centre discussion paper (1051).

Etwire PM, Martey E \& Dogbe W (2013): Technical efficiency of soybean farms and its determinants in Saboba and Chereponi Districts of Northern Ghana: A stochastic frontier approach. Sustainable Agriculture Research 4:106-116.

Hodson, D.P., E. Martinez-Romero, J.W. White, J.D. Carbett, M. Banziger. (2002). Africa Maize Research Atlas.CIMMYT, Mexico, D.F.

Ministry of Food and Agriculture, MoFA (2013): Ministry of Food and Agriculture Districts Report. Retrieved 
September, 2013 from http://mofa.gov.gh

Langyintuo A (2005). Maize production systems in Malawi: setting indicators for impact assessment and targeting. CIMMYT Zimbabwe.

Morris ML, Tripp R \& Dankyi AA (1999): Adoption and impacts of improved maize production technology: A case study of the Ghana grains development project. Economics Program. Mexico, D. F.: CIMMYT.

Olaniyi, O.A. and Manyong, V. (2007). Risk Aversion and Sustainable Maize Production in Nigeria: Some Challenges and Prospects for Agricultural and Economic Development. African Association of Agricultural Economics (AAAE) Conference Proceedings. pp. 177-182.

Olagunju, F.I., Fakayode, S. B., Babatunde, R. O.and Ogunwole-Olapade, F. (2012). Gender Analysis of Sweet Potato Production in Osun State, Nigeria. Asian Journal of Agricultural Extension, Economics and Sociology, 2(1): $1-13$.

Opio, F. (2003). Gender mainstreaming in agriculture with special reference to Uganda: Challenges and prospects. African Crop Science Conference Proceedings, Vol. 6. 699- 703

Simonyan J.B., Umoren, B.D. and Okoye, B.C. (2011). Gender Differentials in Technical Efficiency among Maize Farmers in Essien Udim Local Government Area, Nigeria.International Journal of Economics and Management Sciences, 1(2): $17-23$.

Slingo JM, Challinor AJ, Hoskins BJ, Wheeler TR (2005). Introduction: food crops in a changing climate. Philosophical Transactions of the Royal Society B-Biological Sciences, 360: 1983-1989

Sserunkuuma, D. (2005). The adoption and impact of improved maize and land management technologies in Uganda. 